\title{
The missing colours of chemistry
}

\begin{abstract}
Ingrained prejudices and a lack of action addressing discrimination are some of the main reasons why academic chemistry is overwhelmingly white. Data and discussions on racial inequalities are often greeted with scepticism and cynicism within the community, yet they are necessary to fight racism - and anti-Black racism in particular.
\end{abstract}

\author{
Binuraj R. K. Menon
}

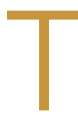

he racial disparities that permeate society have become much more visible - particularly to those who typically have not suffered from such inequities. They have recently been highlighted by the increased profile of the Black Lives Matter movement and protests against police brutality, as well as the COVID-19 pandemic, which has been found to disproportionately affect certain communities, notably Black people ${ }^{1}$. Inequality and racism also prevail in scientific institutions - and chemistry is no exception. The fact that Black chemists are systemically denied access to opportunities and positions at every level in academia is obvious from simply looking at the make-up of research and teaching faculties in the Western world, as well as conferences from small meetings to large international ones. Historically, the world of chemistry has been a very white one and it is important to recognize that this has been perpetuated by systemic racism ${ }^{2,3}$, that is, the policies and practices in place at institutions that inherently disadvantage Black and other minoritized ethnic groups. Note the use of 'minoritized', rather than 'minority', to highlight the dominant power structure that has resulted in social inequities through which certain groups of individuals have less power or representation than others.

\section{The statistics speak for themselves}

In the USA, the National Centre for Science and Engineering Statistics (NCSES) and the Open Chemistry Collaborative in Diversity Equity (OXIDE) have recently released data collected between 2015 and 2018 that clearly show that Black chemists are systematically denied access to academic jobs ${ }^{4}$. As Black people make up about $12.3 \%$ of the US population, in a fair and equitable world one would expect to see a similar representation at every segment of academic life, including undergraduate, graduate, postdoctoral researcher and professor levels. This should hold for other chemistry careers too. Yet, in the academic and educational systems, the percentage of Black people drastically falls at every single stage past the first year

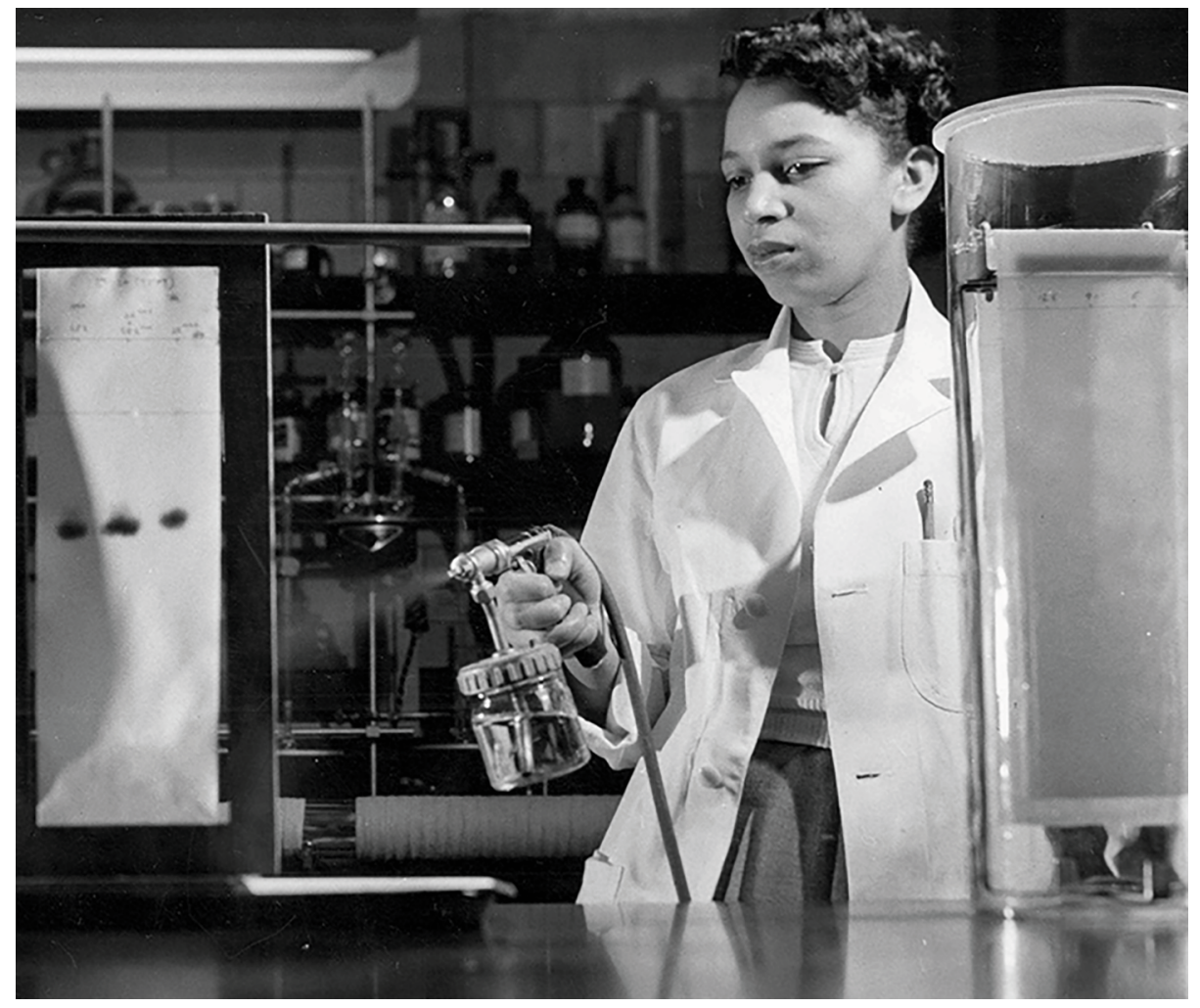

Alma Levant Hayden. Credit: Alto Vintage Images/Alamy Stock Photo

at university. According to the report, Black representation is only $7.9 \%$ among bachelor degree recipients and it further declines to $4.5 \%$ in $\mathrm{PhD}$ recipients, to $3.2 \%$ for postdoctoral researchers in universities and just $1.6 \%$ of chemistry professors at the top 50 schools in the USA.

In the UK, the Royal Society of Chemistry (RSC) diversity landscape report from 2018 showed a very similar situation. The proportion of chemistry students from minoritized ethnic groups falls from $26 \%$ at undergraduate level to $14 \%$ at postgraduate levels; Black and Asian students were shown to be less likely to progress to postgraduate study than their white peers. At professor level, no chemistry-specific data was reported - which is in itself an issue as a more accurate assessment of demographics is necessary to promote change - yet we know that during the academic year $2018 / 2019$ only $0.7 \%$ of all UK university professors (across all fields) were Black. That equates to less than 1 Black professor per higher-education institute in the $\mathrm{UK}^{6}$ (https://go.nature.com/35uubbd). Strikingly though, in both countries, this is in stark contrast to the fact that Black students are found in chemistry departments at first-year university level in percentages that reflect those of the general population (12-13\% for the USA, $3 \%$ in the UK).

Already back in 2006, the RSC and the Institute of Physics jointly published a report on the representation of different ethnic groups in chemistry and physics in the UK, pointing to a drastic drop in numbers from marginalized communities from studying at 


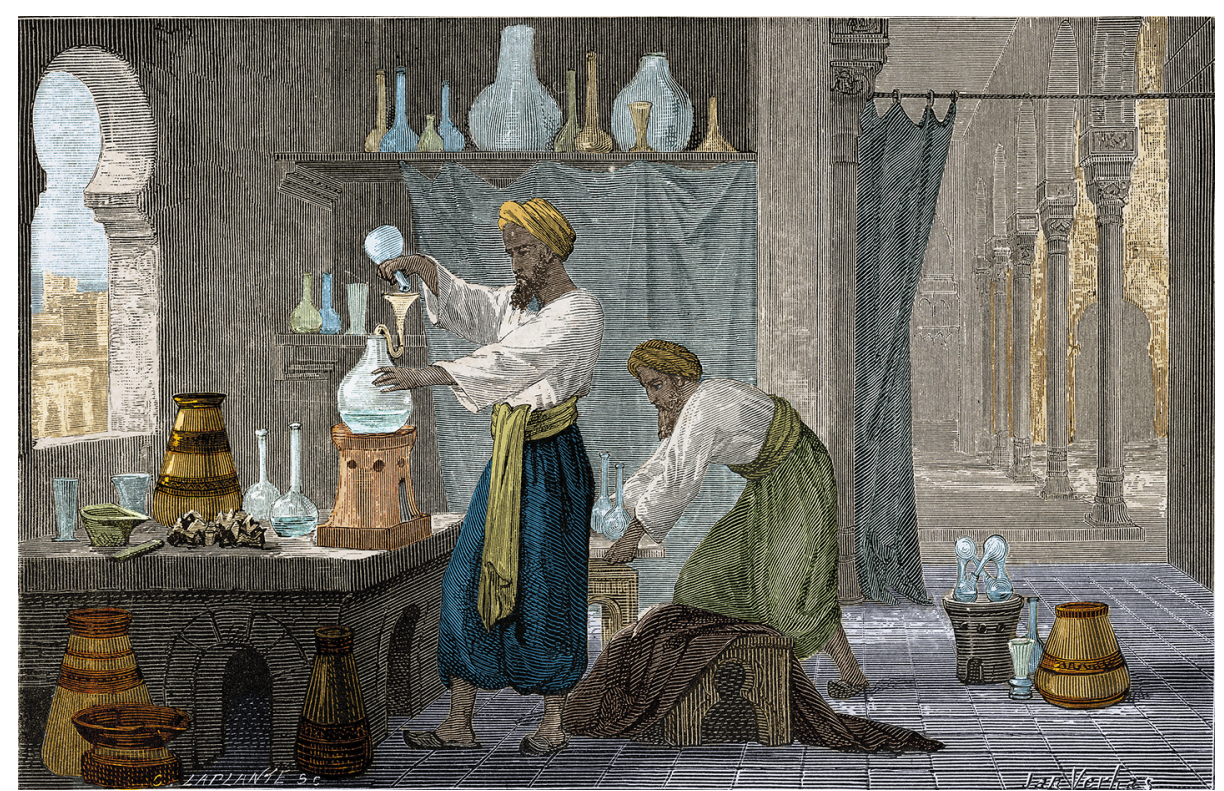

Muhammad ibn Zakariyyā al-Rāzī; Rhazes, Islamic polymath. Credit: Science History Images/Alamy Stock Photo

GCSE level (at the end of secondary school) to pursuing a $\mathrm{PhD}$ in those topics ${ }^{7}$. The similarities with the current statistics make for gloomy reading: the situation has barely changed, despite awareness of the issue.

Clearly, it is important to recognize that minoritized communities aren't a homogeneous group; different people will have different experiences, which in turn needs to be considered when thinking about actions that need to be taken in higher education. It is also important to consider the intersectional nature of oppression that generates unique situations for people who identify with more than one minoritized group; for example, consider the experience of Black women with disabilities over the experience of all Black people. Importantly, the data at hand shows that Black women, in particular, face further barriers in the higher-education sector - they only make up $0.1 \%$ of professors appointed in higher-education institutes across the UK (that is, 25 Black female professors in 2018 , combining all fields $)^{8}$. This and other studies, including those conducted by Nicola Rollock (in 2019) and Iyiola Solanke (in 2017), reveal the unfairness and bias faced by Black women in higher education and their subsequent poor career experiences, with institutions typically asking too much from them, often with no support ${ }^{8-11}$.

Furthermore, these statistics only partly convey the intricacy of the situation. For example, 'postdoctoral level' covers a variety of contracts. It is perhaps the most formative career stage in a researcher's trajectory towards an academic position, and one where many Black people and members of other marginalized groups find it hard to continue a career in academia ${ }^{12,13}$. Recent data from UKRI has also shown that women and minoritized ethnic awardees tended to apply for, and receive, smaller research grants ${ }^{14}$.

Though the reports mentioned above, as well as others ${ }^{15,16}$, only reflect the situation in UK and USA academic institutions, the same trend is also very noticeable in the EU (https://go.nature.com/2MHVZCj). As an example, no Black chemists have been recognized with a Chemistry Europe fellowship since it was established in 2015 (https://chemistry-europe.onlinelibrary. wiley.com/hub/fellows). Chemistry Europe, which consists of 16 chemical societies from 15 European countries and represents over 75,000 chemists, describes this fellowship as "the highest recognition for European chemists to their outstanding support as authors, advisors, guest editors, referees as well as services to their national chemical societies". Another annual reminder of this situation is that, in the over-100-year history of the Nobel Prize, we have never seen a Black scientist - chemist or otherwise be awarded the Nobel prize in Chemistry, Physics, or Physiology or Medicine ${ }^{17}$.

Striving for diversity is simply the right thing to do. No one should be excluded from pursuing a career in science on account of their skin colour, ethnicity, background, gender, disability, sexual orientation or other such criteria typically used to discriminate against people. Building a diverse workforce - more likely to investigate more diverse lines of enquiries than a homogeneous group - is also in good agreement with the scientific method that considers different hypotheses. Yet, higher-education institutes in Western countries struggle to recruit and support a diverse workforce. In my experience, racial and gender disparities - and the associated salary gaps - are discussed very little within academic circles, through recruitments, appointments, promotion processes and, in fact, every decision-making aspect of the academic life. Any discussion of racial discrimination is likely to prompt the raising of eyebrows, cause distress, or at least discomfort, simply by calling attention to it. As Patricia J. Williams once described in her memoir book The Alchemy of Race and Rights, "race is always an invisible elephant in the room".

\section{Selective memory}

"You have to know the past to understand the present", said Carl Sagan. In 1978, in an essay entitled Why Chemistry Needs History and How It Can Get Some, historian Stephen Brush identified that chemists are largely unaware of the history of their discipline and suggested that this could be alleviated by the presence of historians qualified to teach the history of the science in chemistry departments. 43 years on, it is still as relevant ${ }^{18}$. One way to counter racial prejudices is to ensure we remain aware of how science developed throughout history, giving due credit to the contributions from historically marginalized groups but also not forgetting science's involvement in establishing racial bias in society.

The field of alchemy - chemistry's predecessor - is an example of how the earliest contributions from outside Europe have systematically been discredited. Alchemy originated with scholars of the medieval Islamic world. The word alchemy comes from the Arabic 'al-kimiyä', which may be derived from the ancient Egyptian word kemi, meaning black, indicating the rich dark soil of the Nile river valley and its people ${ }^{19}$. It was through the work of alchemists in the medieval Middle East, such as Abū Mūsā Jābir ibn Hayyān and Abū Bakr Muhammad ibn Zakariyyā al-Rāzī (pictured) that alchemy reached its apogee. They introduced the earliest written methods for chemical classification and several protocols in metallurgy and inorganic extraction. The comprehensive thoughts they introduced, which are recorded in old manuscripts and book volumes, went on to pertain not only to chemistry, but also physics and medicine. The contribution of these alchemists also lingers in many chemical names - muriatic 


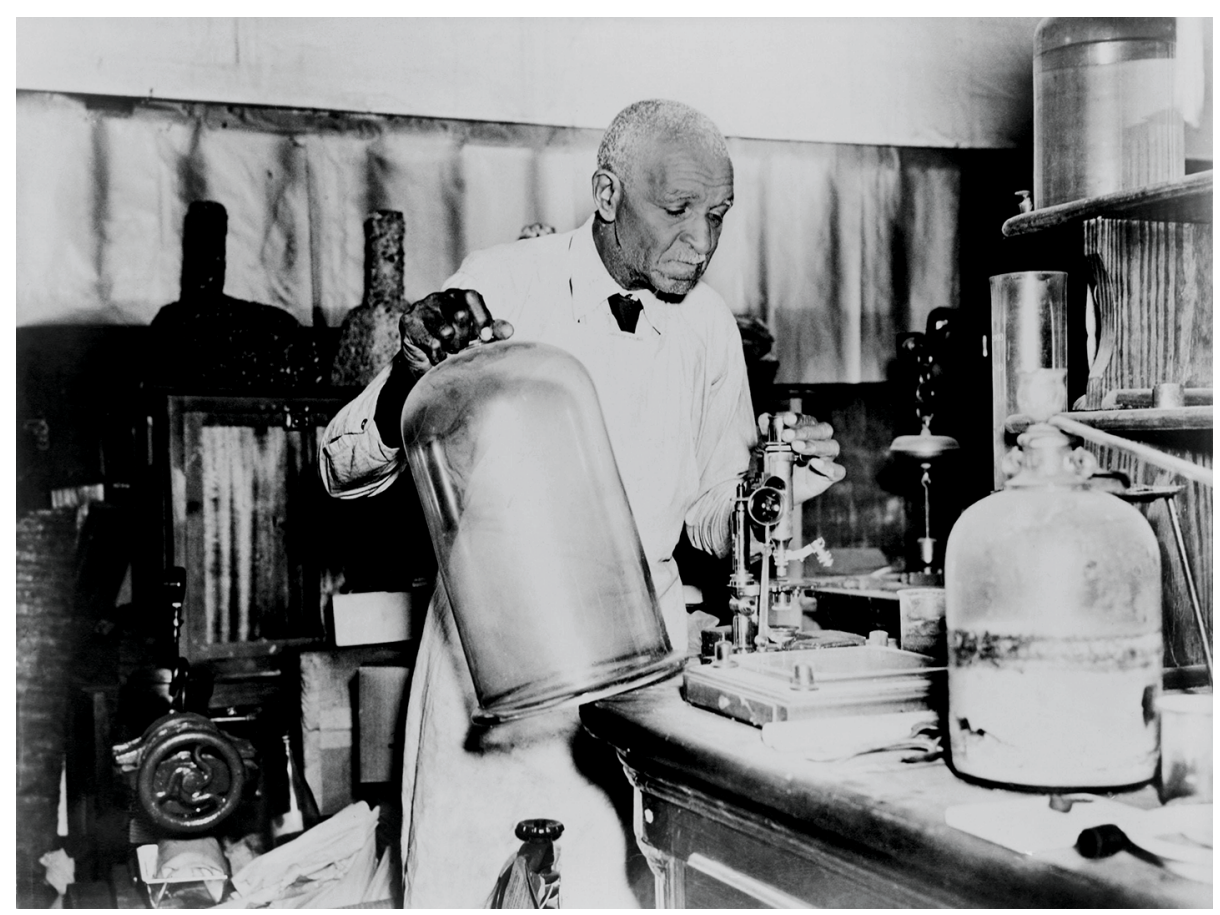

George Washington Carver. Credit: Everett Collection Historical/Alamy Stock Photo

(hydrochloric) acid, sulfuric acid, soda (al-natrun), alkali (al-qali), nitric acid, aqua regia, alcohol (al-kohl), elixir (al-iksir), and alembic (al-inbiq), to name a few. Yet throughout the centuries our knowledge of alchemists has been largely mediated through Latin translators and European colonizers, and it is therefore not surprising that the early discoveries and contributions to the shift from alchemy to science were toned down or ignored to fit their preferred narrative.

Perhaps too often conveniently forgotten, science and racism have been intertwined for centuries, including more recent times ${ }^{20}$. The relationships that existed between the Royal Society in its early years and slave traders such as the Royal African Company (RAC) are documented ${ }^{21}$ and include financial ties until 1699 as well as a significant overlap in membership. Robert Boyle (1627-1691), one of the founders of modern chemistry, carried out investigations on the origin of black skin ${ }^{22}$, which he observed didn't seem directly related to the climate one lived in. His studies on the inheritance of skin colour, along with those of several fellows ${ }^{23}$ of the Royal Society on human differences, contributed to shaping perceptions of human races - and absurd theories of race supremacy - that would go on, over the following decades, to be used to morally justify the brutal treatment of people who had been enslaved ${ }^{24}$. As society evolved, erroneous beliefs about biological differences between people persisted and became insidiously woven into societies' key institutions; for example, they have been linked in the USA to Black people being less likely to be provided with appropriate pain treatment ${ }^{25}$.

Scientists also created the pseudoscientific eugenics movement - with its stated aim of improving the human race by encouraging its fittest members to reproduce. Eugenics was largely adapted from social Darwinism in the late nineteenth century - a gross distortion of Charles Darwin's theory of natural selection, used to rationalise societal inequalities through judgements on which groups were superior or inferior ${ }^{26,27}$. Under the eugenics movement, mass sterilization was developed, in part funded by influential industrialists ${ }^{28}$. They were arguably motivated by eugenics theories for political and financial gains, along with the aim of dominance over marginalized ethnic communities and other vulnerable groups ${ }^{29,30}$. During those periods, and particularly through widespread efforts to curtail the freedom and even the lives of groups judged 'unfit to have children', chemists were called upon, funded and fuelled by the eugenic nexus to develop chemical contraceptives and spermicides ${ }^{28}$. These ideas have been repeatedly and thoroughly debunked yet, very worryingly, they haven't truly disappeared. In the words of Angela Saini, science journalist and author of Superior: The Return of
Race Science, "race science is not about biology, it's about power" (https://go.nature. com/3sbfnYJ); simplistic, pseudoscientific arguments are still invoked today to avoid political responsibility (https://go.nature. com/35qiyly). It is crucial for the scientific community to remain aware of - and continuously fight against - these ideas under any disguise.

It is also important to acknowledge the fact that science isn't the data-driven endeavour, free from any human biases conscious or unconscious - that it is often perceived to be. Policies and practices must be put in place to dismantle the biases that remain embedded in our institutions and individual judgements. As chemists, we must ensure we are aware of our history and we must rectify unfair accounts of the past that carry bias in historical descriptions and interpretations.

\section{Celebrating Black chemists}

Another manifestation of collective amnesia is through the classic chemistry textbooks we follow, which have typically been written by privileged classes. I was, at times, staggered by the fact that most named reactions, which are widespread in particular within the fields of organic chemistry and organometallic catalysis (such as the Fischer-Speier esterification, Prilezhaev epoxidation, Ullmann coupling, Heck reaction) as well as many theorems, physical and chemical laws, rules and equations (for example Hückel's rule, Le Chatelier's principle, Faraday's law, Kasha's rule, Langmuir equation) are, overwhelmingly, named after white men. The prevalence of just one group of people gives the impression that they are the only ones that have made significant contributions to chemistry, in turn sending a signal to students about whether or not they belong in the field. This limited view of the history of chemistry is of course far from the truth, and amending textbooks accordingly would give a fairer representation of the field and its important contributors. Not only should we celebrate Black History Month in our chemistry departments, we should celebrate the historical contributions of Black and other minoritized scientists the whole year round, just as we do with their white male counterparts - this would dispel the myth that chemistry was mostly built by white men.

Throughout history, Black chemists have often encountered hardship, pushed racial barriers, and even had to embrace solitude to carry out scientific research - these are stories that would undoubtedly motivate emerging chemists, beyond their scientific achievements. The life and scientific 
discoveries of Norbert Rillieux (1806-1894), George Washington Carver (1860s-1943), Saint Elmo Brady (1884-1966), Alice Augusta Ball (1892-1916), Lloyd Augustus Hall (1894-1971), Percy Lavon Julian (1899-1975), Charles Richard Drew (19041950), Mary Elliott Hill (1907-1969), Walter Lincoln Hawkins (1911- 1992), Henry Cecil McBay (1914-1995), John E. Hodge (19141996), Henry Aaron Hill (1915-1979), Lloyd Noel Ferguson (1918-2011), Samuel P. Massie (1919-2005), Marie Maynard Daly (1921-2003), Hosea Williams (1926-2000), Alma Levant Hayden (1927-1967), John R. Cooper (1930-2016), James Andrew Harris (1932-2000), Bertram O. Fraser-Reid (1934-2020), Bettye Washington Greene (1935-1995), Jeannette E. Brown (born 1934), Joseph S. Francisco (born 1955), Kelly Chibale (born 1967), Clarice E. Phelps and so many others are typically forgotten ${ }^{31}$. Look them up - learn what they did and bring their names into the mainstream of chemistry. This is a partial list of Black pioneers in chemistry who overcame great odds and went on to make ground-breaking discoveries and developments ${ }^{32}$.

The life of George Washington Carver (pictured) - an agricultural chemist is itself a symbol of anti-racism and for liberation through education. Carver, believed to have been born enslaved, fought against diseases, slavery and poverty ${ }^{33}$. A pioneer in sustainable organic farming, Carver developed several systematic scientific methods for crop-rotation based on soil nitrogen levels in the USA. Percy Lavon Julian - the first African American chemist admitted into the National Academy of Sciences - laid the foundation of synthetic steroid pharmaceutical industry. $\mathrm{He}$ is well known for having carried out the first synthesis of the natural product physostigmine and for the chemical synthesis of many steroid hormones from the plant sterols ${ }^{34,35}$.

Alma Levant Hayden (pictured) was one of the first African American women chemists at the Food and Drug Administration (FDA) in the USA. She was an expert in spectrophotometric analysis of pharmaceutical molecules. In 1963, Levant Hayden was appointed chief of the spectrophotometer research branch in the Division of Pharmaceutical Chemistry ${ }^{36}$. Levant Hayden's name gained wider media attention when she led a team of researchers to analyse the chemical composition of Krebiozen - an expensive, controversial molecule that was once promoted as an anti-cancer drug, but turned out to show no therapeutic effects. Alice Augusta Ball (who died at the young age of 24) was the first woman to receive a Master's degree in chemistry from the University of Hawaii, and the first African American woman to become a chemistry instructor there ${ }^{37}$. The Ball method, an injectable and water-soluble formulation of chaulmoogra tree oil for leprosy treatment, was her pioneering discovery; it was used for effective leprosy treatment for over 20 years in the early twentieth century.

The scientific legacies of Black chemists still impact modern science. Yet, by systematically ignoring their stories and contributions we continue to create generations of chemists who don't appreciate the history of their field and have a very narrow view of its past contributors. This is not only fertile ground to foster biased views in the community on who should or shouldn't be given opportunities to participate, but also means that the chemistry community and wider society more generally miss out on the potential contributions of the people who have been excluded.

\section{Black in the ivory tower}

The fact that systemic racism is a structural problem within organizations - and is arguably unnoticed by many within the majority groups - makes it difficult to report the examples of unfair treatment and racial harassment received by Black researchers in the workplace to employers. Those employees also have the constant worry of being treated less fairly after speaking up, potentially being seen as trouble-makers and subsequently ostracized. Several studies have been conducted by the Equality and Human Rights Commission in the UK. Their survey results suggested that only a minor proportion ( 1 in 5) of racially abusive behaviours and verbal bullying incidents at work places were actually reported and the reported complaints were mostly handled without sufficient seriousness by the employers ${ }^{38,39}$.

The Commission also looked into racial harassment in 2019 after surveying students and staff from publicly funded universities across England, Scotland and Wales ${ }^{40}$. The survey showed that $24 \%$ of minoritized students and more than $25 \%$ of staff members experienced racial harassment; with racist name-calling and insults at the universities being common. 1-in-20 students and 3-in-20 staff members who responded to the survey left their studies or job because of racial harassment, with many more considering quitting ${ }^{38,39}$. After facing racial harassment at these institutions, the students and staff members felt depressed, anxious and vulnerable - with $8 \%$ reporting they had felt suicidal. These reports clearly show the scale of racial bullying and harassment in academia, which has a profound impact on mental health, education and career outcomes. Most importantly, when academic staff members were involved, a large proportion of the incidents took place in office environments in the presence of their colleagues - underscoring the need to raise accountability.

In particular, Black women and early-career Black researchers suffer the devastating effects of institutionalised racism, with very little opportunity for training and promotion ${ }^{41,42}$. In many cases they are made to feel that they do not belong and are regularly subjected to various forms of discrimination, resulting in them leaving academia $^{43}$. To compound the unfairness of the situation, a recent study showed that although women and people from marginalized ethnic groups have exhibited higher innovation rates than those of white men, their contributions are typically overlooked and they have less successful careers as researchers ${ }^{44}$. Furthermore, they are often asked to engage in far more outreach activities and diversity initiatives than their white male counterparts. This additional workload, which can also represent an emotional burden for already thinly stretched researchers, is typically not recognized for career advancement (https://go.nature.com/3nzsteX/).

When Black scholars started to share some of their experiences through the hashtag \#BlackInTheIvory on Twitter from the micro- to the macro-aggressions, including physical threats, that they routinely face in their academic life - many non-Black readers were shocked at just how prevalent anti-Black racism is in academia ${ }^{45}$. This campaign, initiated by Shardé Davis, assistant professor of the University of Connecticut and Joy Melody Woods, $\mathrm{PhD}$ student at the University of Texas-Austin, clearly shows just how difficult academic life can be for Black people in a manner not quite captured by surveys and statistics (https://go.nature.com/2LAaY0G) ${ }^{46}$. Many young Black academics and students expressed their strong disappointment in the constant discouragement they receive from white faculty members, as well as in the institutions that feature them superficially in diversity and inclusion brochures yet foster a hostile environment, taking no steps to actually recognize their achievements ${ }^{47}$. Change will only come from these experiences being acknowledged first, and the fact that these discussions are finally happening is a welcome development. The attention of the community must now be sustained and converted into action importantly, majority groups need to listen, learn and help solve the problems. 


\section{Equity initiatives}

In the USA, the Open Chemistry Collaborative in Diversity Equity (OXIDE) initiative - supported jointly by the National Institutes of Health (NIH), Department of Energy (DOE) and National Science Foundation (NSF) through grants - is working to reduce inequitable policies and practices throughout chemistry departments. OXIDE's activities include the organization of workshops and symposiums, providing diversity resources, and assessing demographic statistics over 75 chemistry departments and publicizing the details in partnership with Chemical \& Engineering News (C\&EN). It also gives recognition to 'diversity leaders' within chemistry departments, selected by the OXIDE team based on diversity activities within departments (http://oxide.jhu.edu/2/ Diversity_Catalyst_Lecturer). The NIH and NSF also promote diversity through different participation, scholarships, training grants and funding programs such as the Alliances for Graduate Education and the Professoriate (AGEP), undergraduate programs at historically Black colleges and universities (HBCU-UP), Louis Stokes Alliances for Minority Participation (LSAMP), and other programs and scholarships (https://extramural-diversity. nih.gov/guidedata/data; https://www.nsf. gov/funding/programs.jsp?org=HRD).

HBCUs, initially founded to offer higher education to Black students and others who were denied attendance at other institutions, today represent about $3 \%$ of all of the USA's higher-education institutions - this small number and their somewhat modest resources, however, don't reflect their importance in the US higher-education system. To mention just one aspect, more than a third of Black students who were awarded a PhD in STEM between 2005 and 2010 had earned their undergraduate degree at an HBCU (https://go.nature. $\mathrm{com} / 3 \mathrm{shdv0O}$ ).

Another notable organization is the National Organization for the Professional Advancement of Black Chemists and Chemical Engineers (NOBCChE), which supports the education and professional development of Black students and professionals (https://www.nobcche.org/ home). The American Chemical Society (ACS) also has its own 'Committee on Minority Affairs' (ChemDiversity), focused on supporting career development and recognition opportunities, and empowering chemists from underrepresented groups (https://www.chemdiversity.org/). In the UK, the RSC plays a major role in diversity and inclusion activities by conducting surveys and compiling diversity reports, amongst other approaches, such as providing diversity grants and awards.

As awareness of the marginalization of academics from minoritized ethnic groups grew in UK universities, a race equality charter (REC) was created in 2015 - inspired by the success of the Athena SWAN charter to support women in STEM - that helps higher-education institutions identify the institutional and cultural barriers faced by minoritized ethnic staff and students ${ }^{48}$. Unfortunately, so far only 75 of the 165 UK higher-education institutes that returned data to the Higher Education Statistics Agency are members of REC, of which only 17 institutes have received a bronze award while none have received silver or gold awards (https://go.nature. com/3hZsBTQ). This is in stark contrast to 164 Athena SWAN members, holding 962 awards amongst them (https://go.nature. com/2MSrZnw). A study of these two charters argues that gender inequalities have been prioritized over racial ones, resulting "in a hierarchy of oppression in which women's experiences have been privileged over that of men and women of colour" ${ }^{49}$.

Over the years, many equality, diversity and inclusion (EDI) activists, academics and organizations have continuously pointed out the systematic inequalities within UK research communities (https:// go.nature.com/2MWeEe1; https://go.nature. $\mathrm{com} / 2 \mathrm{MWdUWh}$ ) and have asked for major reforms to the current procedures and processes by funding bodies and academic institutes, which are highly biased against marginalized groups. Disparities exist not only in selection processes for postgraduate level studies, but also in academic appointments and in research funding allocations (https://go.nature.com/2LbUr3j). The recent attribution of $£ 4.3$ million worth of funding from UK research and innovation (UKRI) and the National Institute for Health Research (NIHR) to explore COVID-19 and its disproportionate impact on Black, Asian and minoritized ethnic communities - none of which were awarded to Black principal investigators - led ten academic Black women to write an open letter to UKRI, addressing research inequality (https://go.nature.com/3s7ihxA). Since then, six further projects have been announced (https://go.nature.com/3q9vJz8).

In 2019, UKRI started releasing some data on the age, disability, ethnicity and gender of the recipients of some of their grants. Though more granular data is needed, the report reflected lower levels of research funding award rates for academics from marginalized backgrounds (https://go.nature.com/3nzqBmr). Recently, UKRI has announced an upcoming funding competition to address inequalities in UK postgraduate courses, and improve participation of Black and other minoritized students ${ }^{50}$. These very welcome initiatives stem from the many reports and action plans put forward by grassroots, volunteer-run organizations such as Leading Routes (https:// leadingroutes.org/), Runnymede (https:// www.runnymedetrust.org/), Black British Academics (https://blackbritishacademics. co.uk/), The Access Project (https://www. theaccessproject.org.uk/), Ladders for action (https://ladders4action.org/), The Inclusion Group for Equity in Research (TIGERS) in STEMM (https://www.tigerinstemm. org/) and the Cowrie Foundation (https:// cowriescholarshipfoundation.org.uk/) to name but a few.

The lack of engagement from universities is similarly bleak in Canada and in the EU. Several reports and news articles have appeared in the last few years that indicate that most higher-education institutions failed to provide data on how their students racially identify ${ }^{51-54}$. As mentioned above, it is necessary to have a clear picture of student and staff diversity through statistics to be able to recognize the issues, the factors at play, and work on providing solutions. All institutions - particularly those with regulatory powers - must engage in diversity and inclusion initiatives, and must take care not to side-step the specific issues relevant to Black people in more general conversations.

\section{Building a better future}

Although the moral obligation should be sufficient to prompt change, perhaps progress in racial equality in higher-education institutes can mainly be accelerated by tangible incentives (including financial), mirroring the promising improvement towards gender balance that was observed in UK academic institutes after Athena SWAN awards were linked to NIHR Biomedical Research Centre (BRC) funding. Institutions could only receive NIHR-BRC funding if they had earned the Silver Award of the Athena SWAN Charter for Women in Science, showing that funding bodies can exert a real influence in this manner ${ }^{55}$.

True racial equality commitments need to come from leaders and departmental heads within universities (https://www.leru. org/files/LERU-EDI-paper_final.pdf). It is hard to believe that a meaningful change will occur without leaders and senior academics being educated on systemic racism and diversity values, listening to the experiences of students and staff from Black and other marginalized groups and being willing to discuss inequality issues. 
A report from Kalwant Bhopal and Clare Pitkin emphasized how REC commitments should be embedded in an institution's structure and culture and championed by a dedicated senior manager rather than encompassed into the existing roles of Equality and Diversity officers ${ }^{56}$. Their recommendations include the development of a safe environment to discuss racism and white privilege, as well as annual reviews of institutions' efforts to address representation of Black and other minoritized academics in senior managerial roles. Candidature and nominations for senior positions in academia - senior research/teaching fellowships, professorships that are provided by Universities and funding bodies - should also specifically consider the mentorship and support, if any, that candidates have provided to marginalized students, as well as whether, and how, they incorporate diversity training and values in their current positions. In fact, a lack of career and academic mentorship from senior academics is often pointed out as one of the factors that push back against minoritized scholars progressing further and is quite critical for chemistry and other STEM subjects.

Crucially, Black academics and other marginalized scholars must be represented at all departmental and university levels and listened to. It is also not sufficient to simply attract higher numbers of students and faculty members from historically marginalized groups. Institutions and the wider community need a profound change and continuous efforts to ensure that these students and academics - and their contributions - are treated and valued in the exact same manner as those from privileged classes ${ }^{57}$. Discriminatory decisions must be pointed out, and those instances taken seriously, so that accountability can be raised at all levels of an institution ${ }^{58}$. A recent example of a decision from institutions undermining their own efforts to attract more diverse students and staff is the introduction of application fees for Master's degree courses at some UK universities. This pattern, first implemented by Imperial College, places barriers at the application level for low-income students (http://go.nature. com/3btYWAS). Additionally, diversity activities - such as Black History Month celebrations - have typically been run by early-career researchers. These programs should instead be embedded in an institution's culture, with senior tenured academic staff and departmental heads taking responsibility for them being held. The time and effort spent on these should also be recognized in the same manner as any other academic exercise.

The chemistry community, and the scientific one more generally, must acknowledge, discuss and fight against these inequalities. The clock is ticking; the time to act is now, for everyone.

Editor's note: This article has been peer-reviewed.

\section{Binuraj R. K. Menon (D)}

Department of Chemistry, Warwick Integrative Synthetic Biology Centre, University of Warwick, Coventry, UK.

Twitter: @Binuraj_Menon

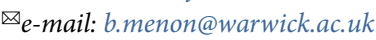

Published online: 29 January 2021

https://doi.org/10.1038/s41557-020-00632-8

\section{References}

1. Hrabowski, F. A. III, Tracy, J. K. \& Henderson, P. H. Proc. Natl Acad. Sci. USA 117, 18137-18141 (2020).

2. Bumpus, N. Nature 583, 661 (2020).

3. Wingfield, A. H. Science 369, 351 (2020).

4. Widener, A. The leaky pipeline for Black chemists. Chem. Eng. News https://go.nature.com/leakypipeline (2020).

5. Diversity Landscape of the Chemical Sciences: A Report by the Royal Society of Chemistry (RSC, 2018); https://go.nature.com/2v7mdfv

6. Higher Education Staff Statistics: UK, 2018/19 (HESA, 2020); https://go.nature.com/3hZwMyP

7. Ahmed, S., Dickinson, S., Hollinshead, K. McWhinnie, S \& Panesor, T. Representation of Ethnic Groups in Chemistry and Physics (IOP and RSC, 2006); https://go.nature.com/38vYosx

8. Rollock, N. Staying Power: The Career Experiences and Strategies of UK Black Female Professors (University and College Union, 2019); https://go.nature.com/3ouhogf

9. Adams, R. Black female professors must deal with bullying to win promotion, report finds. The Guardian https://go.nature. com/399yABo (2019).

10. Grove, J. Black female academics in UK 'face pervasive bullying'. Times Higher Education https://go.nature.com/2JWdWvY (2019).

11. Flaherty, C. The souls of Black professors. Inside Higher Ed https://go.nature.com/3bl3VDT (2020).

12. Eisen, A. \& Eaton, D. C. CBE: Life Sci. Educ. 16, ar65 (2017).

13. Yadav, A. \& Seals, C. Int. J. of STEM Educ. 6, 15 (2019).

14. Diversity Results for UKRI Funding Data (UKRI, 2020); https://go.nature.com/3nzqBmr

15. Bhopal, K. The Experiences of Black and Minority Ethnic Academics: A Comparative Study of the Unequal Academy 1-162 (Routledge, 2015).

16. A Picture of the UK Scientific Workforce: Diversity Data Analysis for the Royal Society Summary Report (The Royal Society, 2014); https://go.nature.com/2MLr2gK

17. Morgan, W. No black scientist has ever won a Nobel - that's bad for science, and bad for society. Phys.org https://phys.org/ news/2018-10-black-scientist-won-nobel-bad.html (2018).

18. Seeman, J. I. Found. Chem. 20, 75-86 (2017).

19. Rāshid, R. \& Morelon, R. (eds) Encyclopedia of the History of Arabic Science (Routledge, 1996).

20. Marks, J. Is science racist? (Polity Press, 2017).

21. Govier, M. Notes Rec. R. Soc. Lond. 53, 203-217 (1999).

22. Boyle, R. A Picture of the UK Scientific Workforce; Diversity Data Analysis for the Experiments and Considerations Touching Colours: First Occasionally Written Among Some Other Essays to a Friend and Now Suffer'd To Come Abroad As the Beginning of an Experimental History of Colours (Printed for Henry Herringman, 1670).
23. Malcolmson, C. in Studies of Skin Color in the Early Royal Society: Boyle, Cavendish, Swift (Routledge, 2016).

24. Yale, E. The deep-rooted racism of science. Quartz https:// go.nature.com/35EnW4T (2016).

25. Hoffman, K. M., Trawalter, S., Axt, J. R. \& Oliver, M. N. Proc Nat Acad. Sci. USA 113, 4296-4301 (2016).

26. MacKenzie, D. Soc. Stud. Sci. 6, 499-532 (1976).

27. Soloway, R. A. Demography and Degeneration: Eugenics and the Declining Birthrate in Twentieth-Century Britain (Univ. North Carolina Press, 1990).

28. Löwy, I. Br. J. Hist. Sci. 44, 245-274 (2011).

29. Schenk, F. \& Parkes, A. S. Eugen. Rev. 60, 142-161 (1968).

30. Kevles, D. J. BMJ 319, 435-438 (1999).

31. Satyanarayana, M. Black chemists you should know about. Chem. Eng. News http://go.nature.com/38FysKY (2020).

32. Bastian, H. Black History Month: Chemists' powerful stories \& the sociologist who studied them. PLOS https://go.nature. com/3onizy9 (2020).

33. Carver, G. W. \& Kremer, G. R. George Washington Carver in His Own Words (Univ. Missouri Press, 1987).

34. Kyle, R. A. \& Shampo, M. A. Mayo Clin. Proc. 71, 1170 (1996).

35. Ravin, J. G. \& Higginbotham, E. J. Arch. Ophthalmol. 127, 690-692 (2009).

36. Rossiter, M. W. Women Scientists in America: Before Affirmative Action, 1940-1972 Vol. 2 (Johns Hopkins Univ. Press, 1995).

37. Brown, J. E. African American Women Chemists (Oxford Univ. Press, 2012).

38. Racial Harassment Inquiry: Survey of University Students Research Report No. 129 (Equality and Human Rights Commission, 2019); https://go.nature.com/2Lk8i7D

39. Tackling Racial Harassment: Universities Challenged (Equality and Human Rights Commission, 2019); https://go.nature. com/39lWOZ7

40. Racial Harassment in British Universities: Qualitative Research Findings (Equality and Human Rights Commission, 2019); https://go.nature.com/39fl9jq

41. Morton, T. R. \& Parsons, E. C. Sci. Ed. 102, 1363-1393 (2018).

42. Prescod-Weinstein, C. Signs 45, 421-447 (2019).

43. Gewin, V. Nature 583, 319-322 (2020).

44. Hofstra, B. et al. Proc. Natl Acad. Sci. USA 117, 9284-9291 (2020).

45. Freund, C. Black scientists are exposing the racist side of academia on Twitter. Massive Science https://go.nature. com/38uS5Ft (2020).

46. Subbaraman, N. Nature 582, 327 (2020).

47. Viglione, G. Chemists grapple with lack of diversity displayed in 'dude walls' of honor. Chem. Eng. News https://go.nature. com/3i2eX23 (2019).

48. Bhopal, K. White academia: will the Race Equality Charter make a difference? LSE https://go.nature.com/3i4Y3Aa (2016).

49. Bhopal, K. \& Henderson, H. Educ. Rev. https://doi.org/10.1080/00 131911.2019.1642305 (2019).

50. UKRI. Notice of a joint Research England and Office for Students funding competition to reduce inequalities in postgraduate research study. The National Archives https://go.nature. com/35x0lmy (2020).

51. Charbonneau, L. Most universities report having equity, diversity and inclusion plans, but challenges remain. University Affairs https://go.nature.com/3saYJs9 (2019).

52. Gordon, A. Lack of diversity persists among teaching staff at Canadian universities, colleges, report finds. https://go.nature. com/3ozxKo6 (2018).

53. Diversity, equity and inclusion: strategic issues for universities. European University Association https://eua.eu/news/426:diversity, $\% 20$-equity-and-inclusion-strategic-issues-for-universities.html (2019).

54. Robson, K. Why won't Canada collect data on race and student success? The Conversation https://go.nature.com/38zjTby (2018).

55. Ovseiko, P. V. et al. BMJ 371, m3975 (2020).

56. Bhopal, K \& Pitkin, C. Investigating Higher Education Institutions and Their Views on the Race Equality Charter (University and College Union, 2018); https://go.nature.com $/ 38 \mathrm{w} 4 \mathrm{kBr}$

57. Forrester, N. Nature 585, S65-S67 (2020).

58. Mehta, D. Nature 559, 153 (2018).

\section{Competing interests}

The author declares no competing interests. 